\title{
CFD Modeling of Spray Formation in Diesel Engines
}

\author{
By Mohamed Maher* \\ Ahmed Abu-Elhamyel ${ }^{\dagger}$ \\ Omar Hassant \\ Alaa El-Din Ramadan \\ Aya Diab \\ Mostafa Abdelkhalek \\ Adham Mohamed \\ Mohamed Abdel-Hay
}

Growing concern regarding energy resources and the environment has increased interest in developing Diesel engines for better fuel economy and lower emissions. A three dimensional CFD simulation of a 4-stroke engine is developed for a Ruggerini RD 270 engine using internal combustion engine module in ANSYS-FLUENT. A cold flow simulation is performed first to visualize the air motion inside the cylinder and to detect the changes of air properties through the different strokes of the engine. This simulation is validated against a compression test performed on the engine at the "Green Energy Lab" at Faculty of Engineering, Ain Shams University. To test the spray formation model before applying it in the engine model, a simulation of Diesel spray in a constant volume chamber is performed and validated against the experimental data by Park et al. (2010). Integration of engine model and spray model is then performed. A comparison of variation of penetration length for different injection pressures and diameters is made.

Keywords: Breakup model, Cold flow simulation, Hydrodynamic instability, IC-engine, Injection nozzle, Penetration length, Spray formation.

\section{Introduction}

The design of internal combustion (IC) engines is under significant pressure for improvement. The next generation of engines needs to be light, compact, powerful, and flexible, yet produce less pollution and use less fuel. To meet these competing requirements, innovative engine designs will be needed. The ability

\footnotetext{
* Ain Shams University, Egypt.

${ }^{\dagger}$ Ain Shams University, Egypt.

* Ain Shams University, Egypt.

- Ain Shams University, Egypt.

Ain Shams University, Egypt.

- Ain Shams University, Egypt

* Ain Shams University, Egypt.

^Ain Shams University, Egypt.
} 
to analyze the performance of multiple engine designs accurately and rapidly is also becoming critical.

One of the recent developments is the use of biodiesel engines which are engines fueled with petrol Diesel fuel blended with biofuels. Usage of biofuels in IC engines is opening the door to a new era in engines development since they can be considered as renewable sources of energy that can stand against oil depletion problem. Many researches are conducted to study biodiesel engines performance alongside with their environmental impact.

Although biodiesel is non-toxic, produced from renewable resources, can be used in existing Diesel engines, and produces less greenhouse gas emissions, it was found to have some drawbacks. One of its main drawbacks is the presence of water and residual alcohol in biodiesel which may generate an unwanted reaction, producing free fatty acids that can lead to metallic corrosion especially with aluminum which comprises most of engine parts in recent times (Munoz et al., 2012). So the challenge is to introduce a biodiesel with the highest blending ratio but at the same time can run the engine without modification for existing engines or usage of more expensive materials for manufacturing the new engines.

A computational fluid dynamics (CFD) modeling of the spray formation process in a Diesel engine is developed in ANSYS-FLUENT using its discrete phase modeling (DPM) capability and its IC-engine module.

\section{Engine Model}

The engine under consideration is a Ruggerini RD 270 engine with the specifications shown in Table 1 (Ruggerini, 2003):

Table 1. Ruggerini RD 270 Specifications

Number of cylinders

Cooling

Bore

Stroke

Swept volume

Compression ratio

Clearance

Connecting rod

Crank radius

Injector hole diameter

Rated power

2
Air cooled
$95 \mathrm{~mm}$
$85 \mathrm{~mm}$
$1205 \mathrm{cc}$
$18: 1$
$4.7 \mathrm{~mm}$
$187 \mathrm{~mm}$
$42.5 \mathrm{~mm}$
$0.28 \mathrm{~mm}$

$20 \mathrm{kw}(27.2 \mathrm{Hp})$
@ $3000 \mathrm{rpm}$

The performance of an IC engine depends upon the complex interactions between fluid dynamics of turbulent reacting flows and the engine moving parts e.g. the intake and exhaust valves and the piston over a particularly short period of time scale which adds to the complexity.

As a starting point, a cold flow investigation is undertaken to study the air motion inside the engine's combustion chamber as well as the spray formation without combustion. 
Figure 1. Engine Geometry

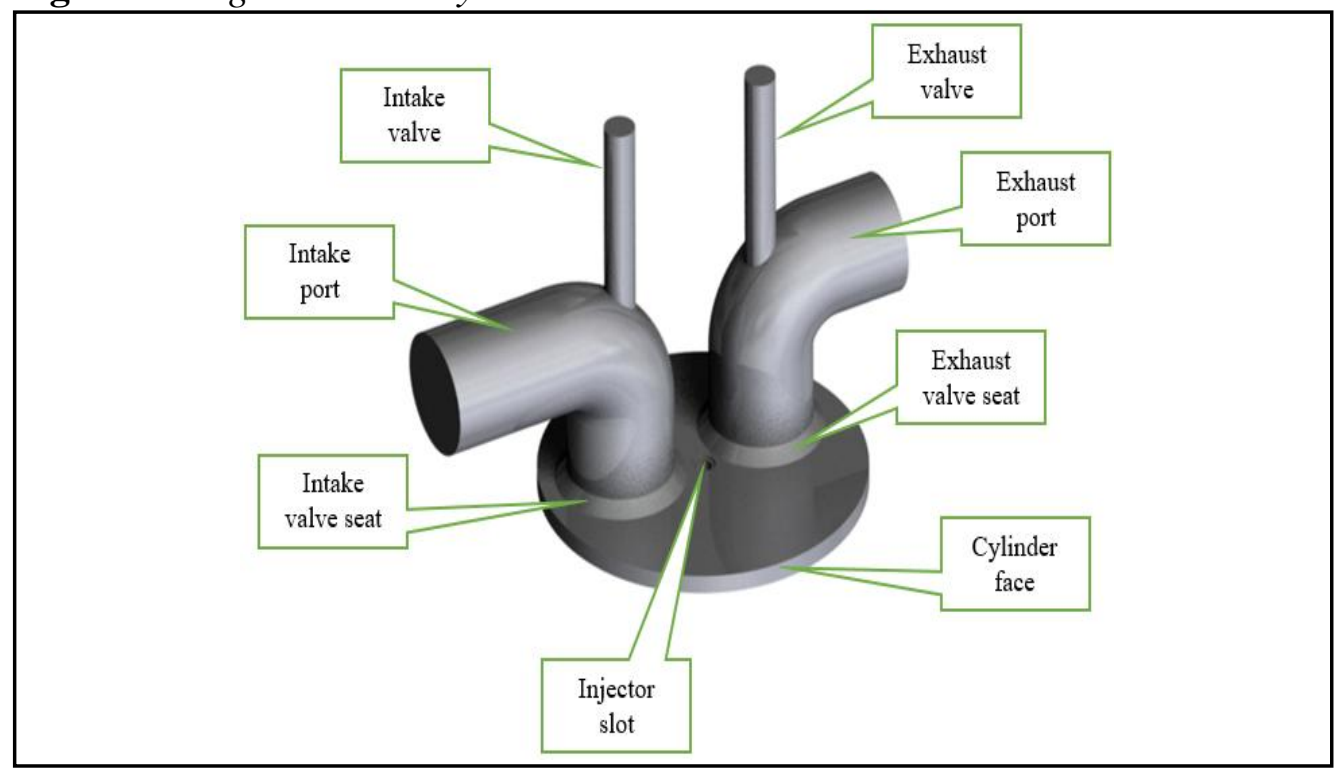

Figure 2. Detailed View of Engine Geometry
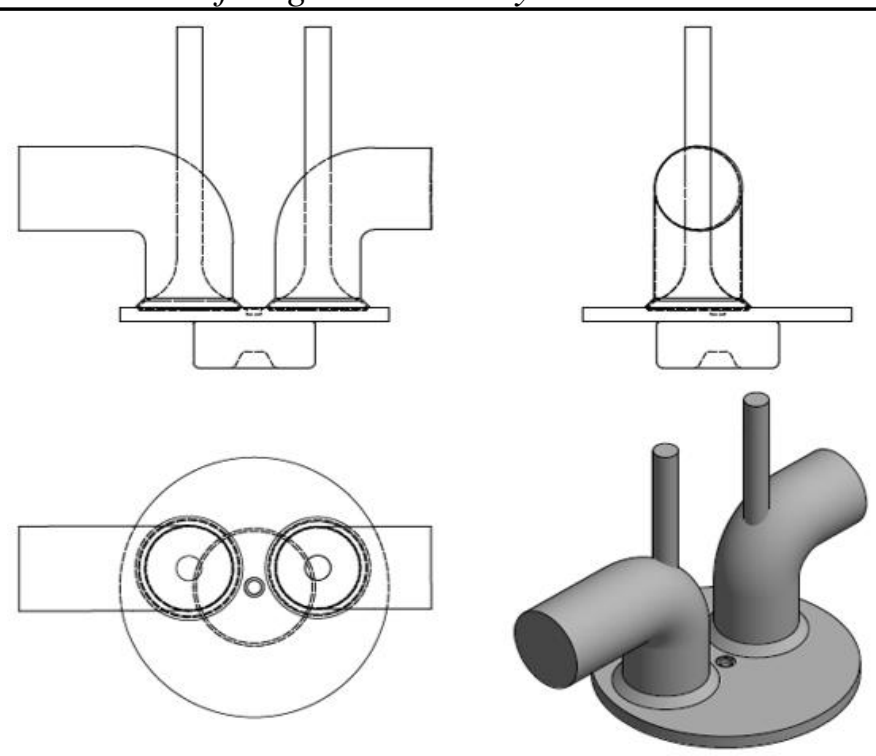

A three-dimensional (3D) geometry of the engine is created using Inventor CAD software as shown in Figures 1 and 2 and the geometry is imported to the DesignModeler in the "IC Engine" module of ANSYS-FLUENT where it is decomposed as shown in Figure 3 to facilitate the meshing process. After decomposition, the engine is divided into three regions: valve, port and chamber regions. Each region is subdivided into smaller parts to allow generating a fixed or a moving (dynamic) mesh depending on the engine kinematics; for example: the chamber region between the cylinder head and the piston needs a layering mesh that can expand or collapse during the motion of the piston. The created mesh is shown in Figures 4 and 5. 
Figure 3. Decomposed Geometry

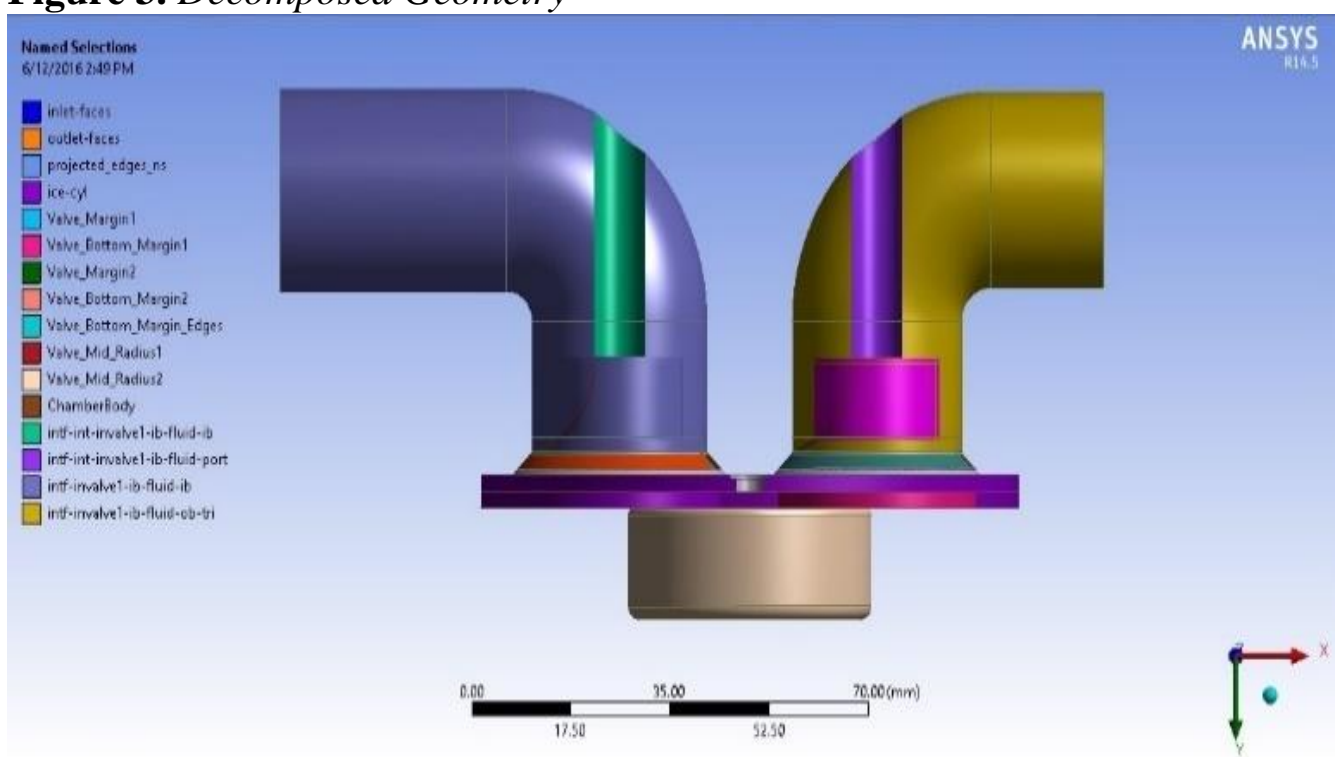

Figure 4. Geometry Mesh of the Engine

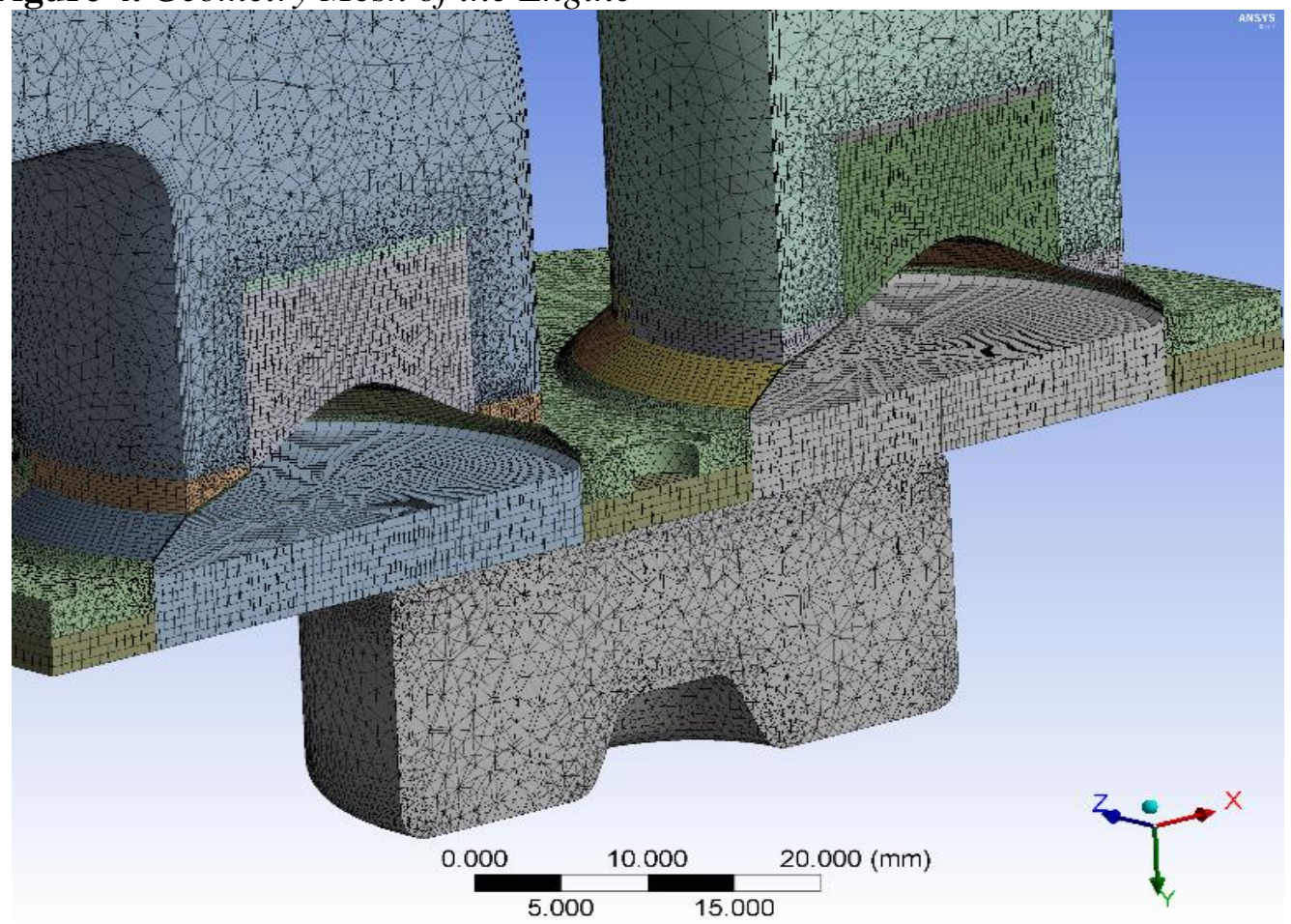


Figure 5. Mesh Around the Valve

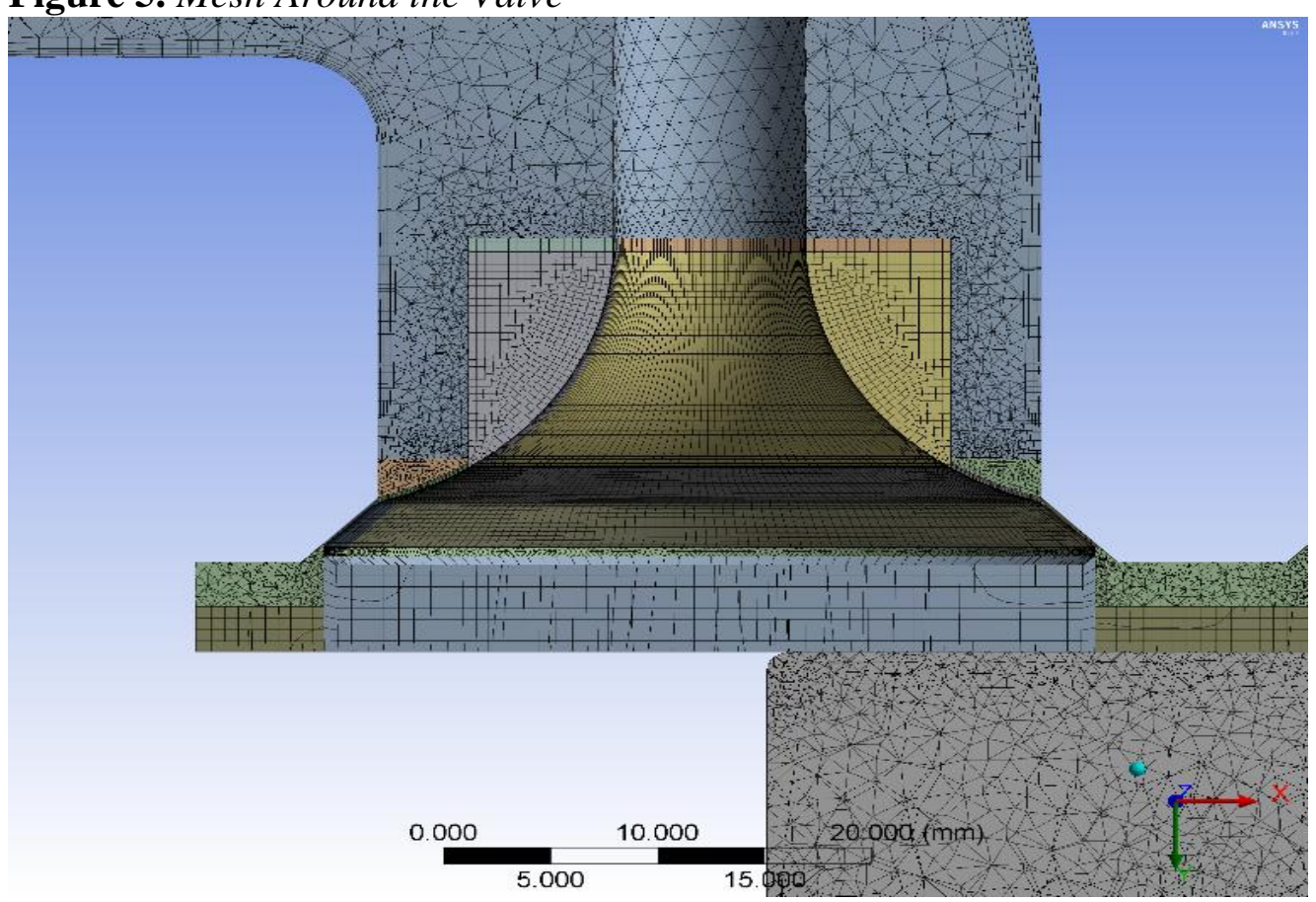

The motion of the piston is specified as a single degree of freedom motion close to a sinusoidal profile as a function of the engine's crank angle, crank radius, connecting rod length and engine speed. The piston location is calculated using

$$
p_{s}=L+\frac{A}{2}\left(1-\cos \left(\theta_{c}\right)\right)-\sqrt{L^{2}-\frac{A^{2}}{4} \sin ^{2}\left(\theta_{c}\right)}
$$

where $p_{s}$ is the piston location ( 0 at the top dead center (TDC) and $A$ at the bottom dead center (BDC)), $L$ is the connecting rod length, $A$ is the piston stroke, and $\theta_{c}$ is the current crank angle. The current crank angle is calculated from

$$
\theta_{c}=\theta_{s}+t . N
$$

where $\theta_{s}$ is the starting crank angle and $N$ is the crank shaft speed (ANSYS). 
Figure 6. Piston Lift Profile

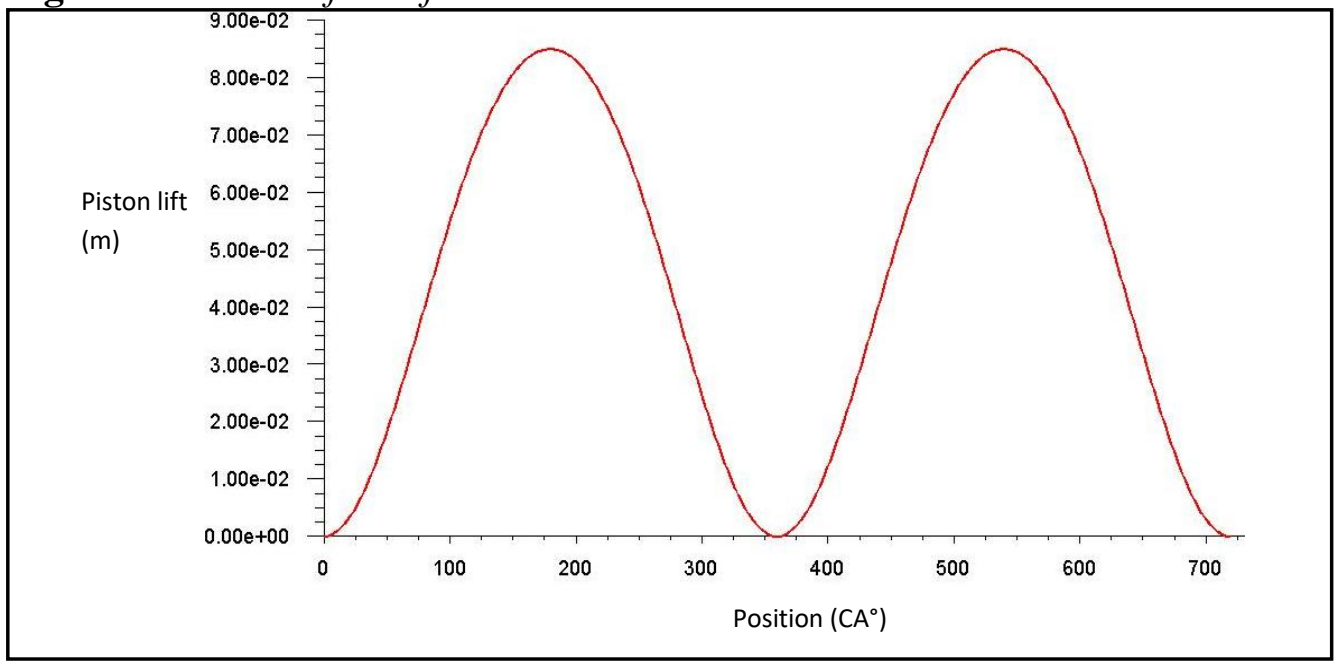

The valves lift profile is developed in accordance with measurements from the engine. The piston and valve lift profiles are shown in Figures 6 and 7. The simulation is started when the piston is at the top dead center towards the end of the compression stroke.

Figure 7. Valves Lift Profile

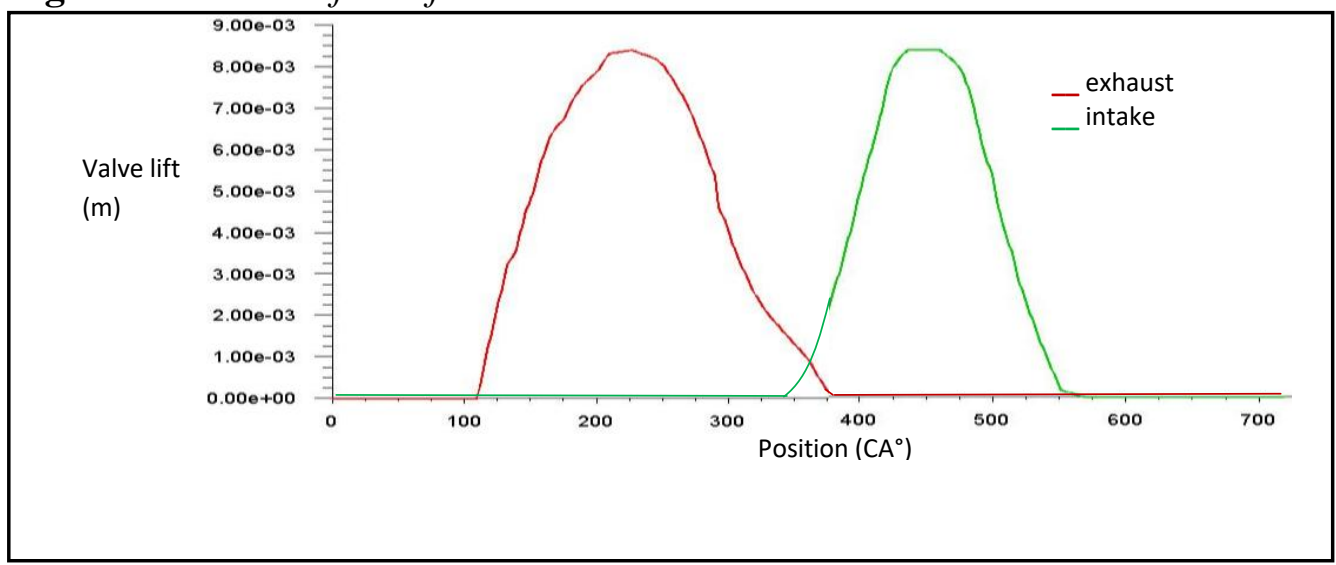

These profiles govern the mesh deformation throughout the engine simulation.

Mass, momentum and energy equations alongside with $\mathrm{k}-\varepsilon$ turbulence model are used in the Eulerian frame of reference to model the air flow through the engine.

The mass equation is given by

$$
\frac{\partial}{\partial t}\left(\rho_{a}\right)+\frac{\partial}{\partial x}\left(\rho_{a} u\right)+\frac{\partial}{\partial y}\left(\rho_{a} v\right)+\frac{\partial}{\partial z}\left(\rho_{a} w\right)=s_{\text {mass }}
$$


where $\rho_{a}$ is the density of the air, $u, v$ and $w$ are the velocity components of axes $x, y$ and $z$ respectively and $s_{\text {mass }}$ is the source term due to mass exchange between the air and fuel droplets (evaporation) after the injection.

The momentum equation for $x$ axis is given by

$$
\begin{aligned}
& \frac{\partial}{\partial t}\left(\rho_{a} u\right)+\frac{\partial\left(\rho_{a} u^{2}\right)}{\partial x}+\frac{\partial\left(\rho_{a} u v\right)}{\partial y}+\frac{\partial\left(\rho_{a} u w\right)}{\partial z} \\
= & -\frac{\partial P}{\partial x}+\frac{\partial \tau_{x x}}{\partial x}+\frac{\partial \tau_{y x}}{\partial y}+\frac{\partial \tau_{z x}}{\partial z}+\rho_{a} g_{x}+s_{\text {mom }_{i}}
\end{aligned}
$$

where $P$ is the pressure, $\tau_{x x}$ is the normal stress in $x$ direction, $\tau_{y x}$ and $\tau_{z x}$ are the shear stresses parallel to $x$ and normal to $y$ and $z$ respectively and $s_{m_{m} m_{i}}$ is the momentum source term due to momentum exchange between the air and the fuel droplets. The momentum equations for the other two axes are similar to $x$ axis equation.

The energy equation is given by

$$
\begin{gathered}
\frac{\partial}{\partial t}\left[\rho_{a} \alpha_{a}\left(i_{a}+\frac{v^{2}}{2}\right)\right]+\nabla \cdot\left[\rho_{a} \alpha_{a}\left(i_{a}+\frac{v^{2}}{2}\right) \vec{v}\right] \\
=\rho \dot{q}+\frac{\partial}{\partial x}\left(k_{\text {eff }} \frac{\partial T}{\partial x}\right)+\frac{\partial}{\partial y}\left(k_{\text {eff }} \frac{\partial T}{\partial y}\right) \\
+\frac{\partial}{\partial z}\left(k_{\text {eff }} \frac{\partial T}{\partial z}\right)-\frac{\partial(u P)}{\partial x}-\frac{\partial(v P)}{\partial y}-\frac{\partial(w P)}{\partial z}+\frac{\partial\left(u \tau_{x x}\right)}{\partial x} \\
+\frac{\partial\left(u \tau_{y x}\right)}{\partial y}+\frac{\partial\left(u \tau_{z x}\right)}{\partial z}+\frac{\partial\left(v \tau_{x y}\right)}{\partial x}+\frac{\partial\left(v \tau_{y y}\right)}{\partial y}+\frac{\partial\left(v \tau_{z y}\right)}{\partial z} \\
+\frac{\partial\left(w \tau_{x z}\right)}{\partial x}+\frac{\partial\left(w \tau_{y z}\right)}{\partial y}+\frac{\partial\left(w \tau_{z z}\right)}{\partial z}+\rho \vec{g} \cdot \vec{v}+s_{\text {energy }}
\end{gathered}
$$

where $\alpha_{a}$ is the void fraction of the air, $i_{a}$ is the air internal energy, $v$ is the flow velocity $\dot{q}$ is the rate of volumetric heat addition per unit mass, $k_{\text {eff }}$ is the effective thermal conductivity, and $s_{\text {energy }}$ is the energy coupling term with the dispersed phase.

To model the air turbulence inside the chamber, the standard $k-\varepsilon$ model was used. The transport equations of this model are given by

$$
\begin{gathered}
\frac{\partial}{\partial t}(\rho k)+\frac{\partial}{\partial x_{i}}\left(\rho k u_{i}\right) \\
=\frac{\partial}{\partial x_{j}}\left[\left(\mu+\frac{\mu_{t}}{\sigma_{k}}\right) \frac{\partial k}{\partial x_{j}}\right]-\rho \overline{u_{l}^{\prime} u_{j}^{\prime}} \frac{\partial u_{j}}{\partial x_{i}}-\frac{1}{\rho}\left(\frac{\partial \rho}{\partial T}\right)_{p} g_{i} \frac{\mu_{t}}{P r_{t}} \frac{\partial T}{\partial x_{i}}-\rho \varepsilon-2 \rho \varepsilon M_{t}^{2}
\end{gathered}
$$

and 


$$
\begin{gathered}
\frac{\partial}{\partial t}(\rho \varepsilon)+\frac{\partial}{\partial x_{i}}\left(\rho \varepsilon u_{i}\right)=\frac{\partial}{\partial x_{j}}\left[\left(\mu+\frac{\mu_{t}}{\sigma_{\varepsilon}}\right) \frac{\partial \varepsilon}{\partial x_{j}}\right] \\
+C_{1 \varepsilon} \frac{\varepsilon}{k}\left(-\rho \overline{u_{\imath}^{\prime} u_{j}^{\prime}} \frac{\partial u_{j}}{\partial x_{i}}-C_{3 \varepsilon} \frac{1}{\rho}\left(\frac{\partial \rho}{\partial T}\right)_{p} g_{i} \frac{\mu_{t}}{P r_{t}} \frac{\partial T}{\partial x_{i}}\right)-C_{2 \varepsilon} \rho \frac{\varepsilon^{2}}{k}
\end{gathered}
$$

where $k$ is the turbulent kinetic energy, $\varepsilon$ is the turbulent kinetic energy dissipation rate, $\mu_{t}$ is the turbulent viscosity, $P r_{t}$ is the turbulent Prandtl number, $M_{t}$ is the turbulent Mach number and $C_{1 \varepsilon}, C_{2 \varepsilon}, C_{\mu}, \sigma_{k}$ and $\sigma_{\varepsilon}$ are constants (ANSYS; Crowe et al., 1998).

The spatial discretization of the governing equations is set to second order upwind scheme for higher accuracy. The temporal discretization is done by setting the solution time step to be equal to the time of 0.25 degree crank angle. At a speed of $3000 \mathrm{rpm}$, this time step is nearly equal to $1.39 \times 10^{-5}$ second which is small enough to appropriately resolve variations during the engine simulation.

The velocity contours of the chamber for the cold flow simulation at various crank angles were obtained as shown in Figure 8.

Figure 8. Velocity Contours $\left(0^{\circ}\right.$ is the Start of Expansion Stroke)

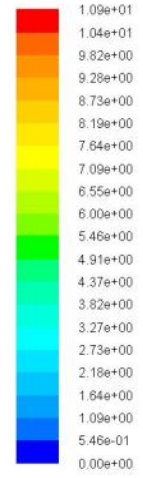

Crank angle $4^{\circ}$

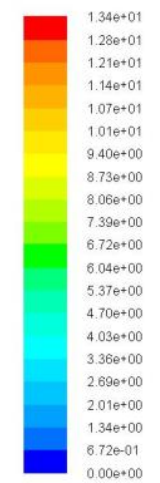

Crank angle $88^{\circ}$
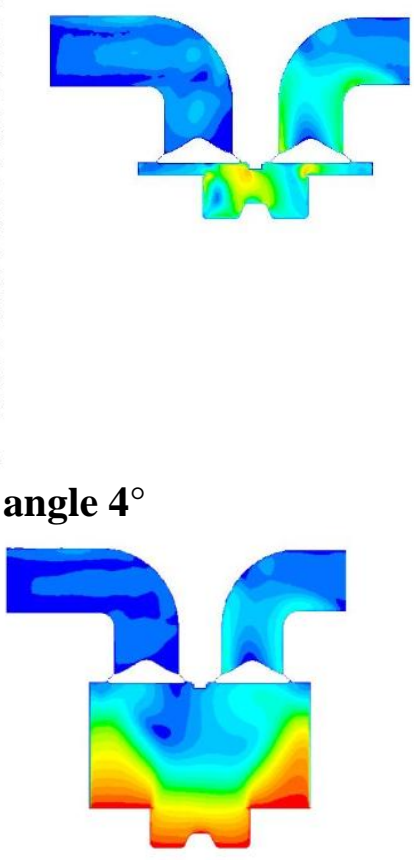

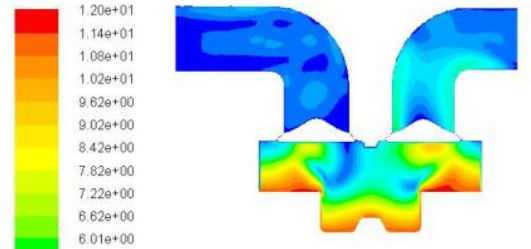

$5.416+00$
$4.81++00$
$4.21++00$
$3.61++00$
$3.01++00$
$2.416+00$
$1.800+00$
$1.200+00$
$6.01 e-01$
$0.00 e+00$

\section{Crank angle $44^{\circ}$}

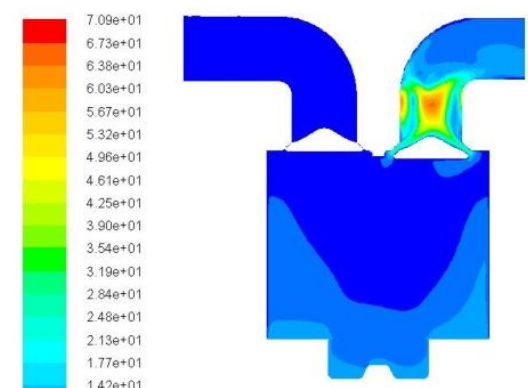




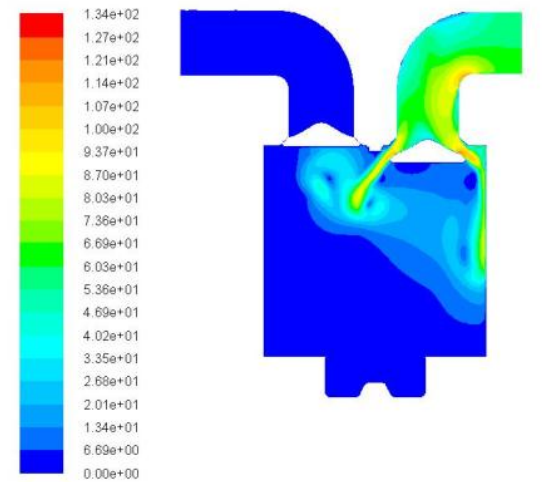

Crank angle $176^{\circ}$

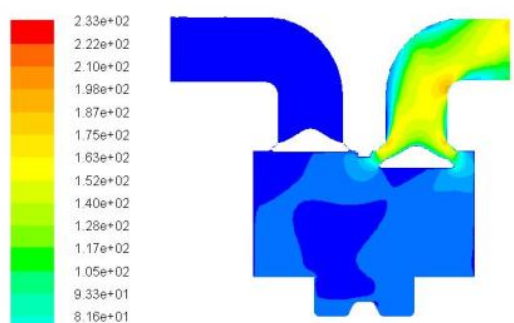

Crank angle $264^{\circ}$

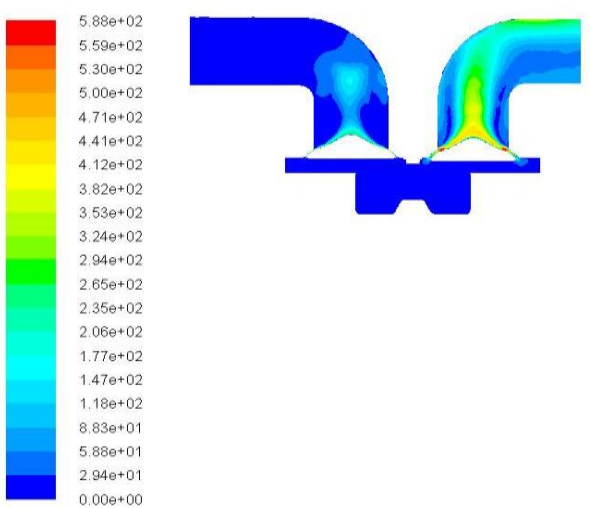

Crank angle $348^{\circ}$

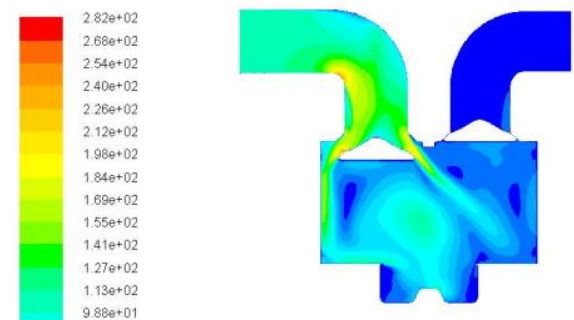

Crank angle $452^{\circ}$

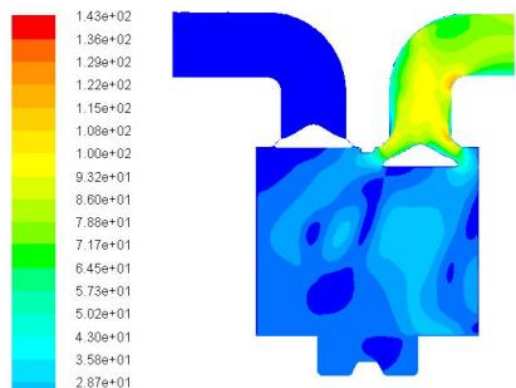

Crank angle $220^{\circ}$

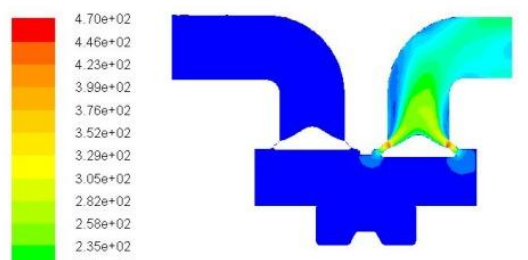

Crank angle $308^{\circ}$
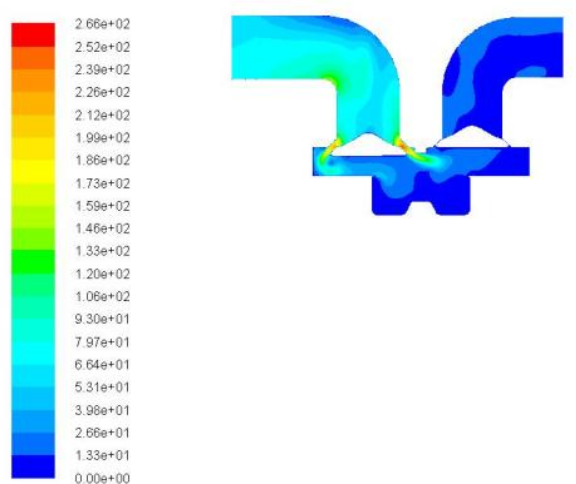

Crank angle $392^{\circ}$
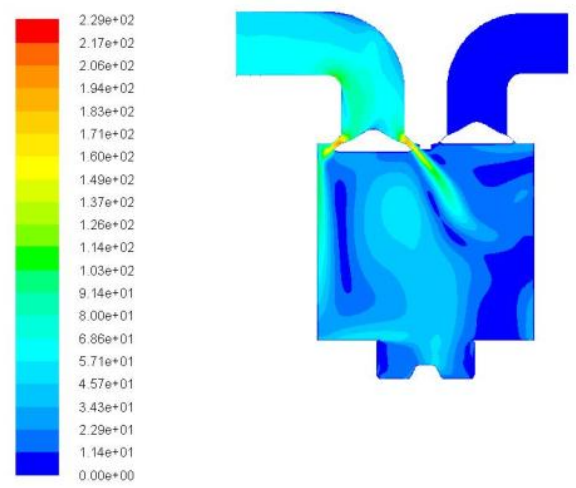

Crank angle $512^{\circ}$ 

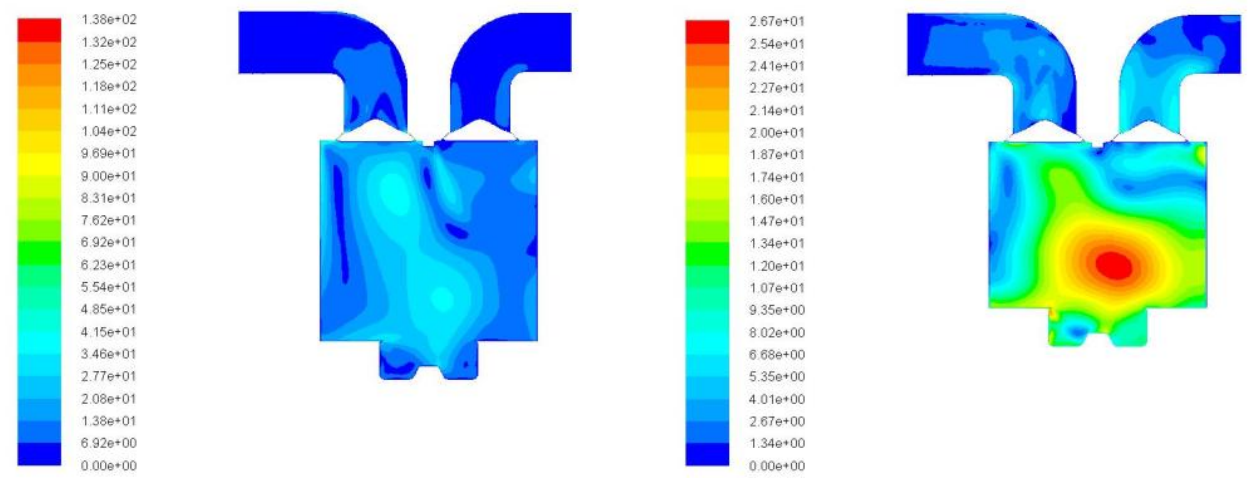

Crank angle 548

Crank angle $596^{\circ}$
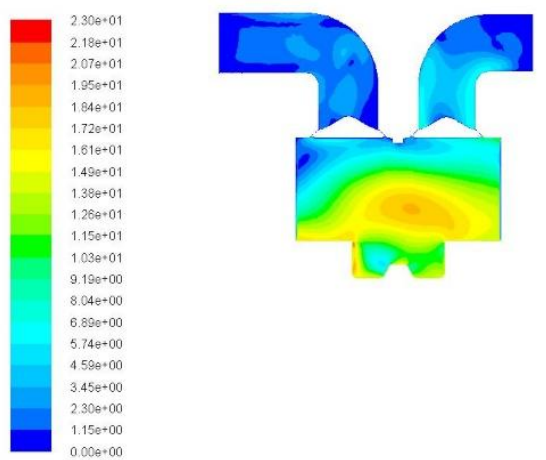

Crank angle $636^{\circ}$

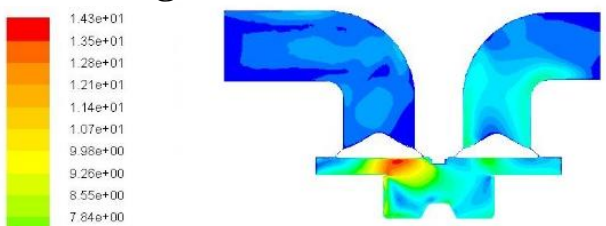

The maximum air velocity at the intake stroke or exhaust stroke well exceeds $100 \mathrm{~m} / \mathrm{s}$, which implies that high turbulence levels are achieved inside the chamber. It is also obvious that the piston configuration enhances the air turbulence which leads to the formation of a vortex inside the chamber as found by the tumble ratio graph detected from the simulation shown in Figure 9 (Sushma and Jagadeesha, 2013).

Figure 9. Tumble Ratio

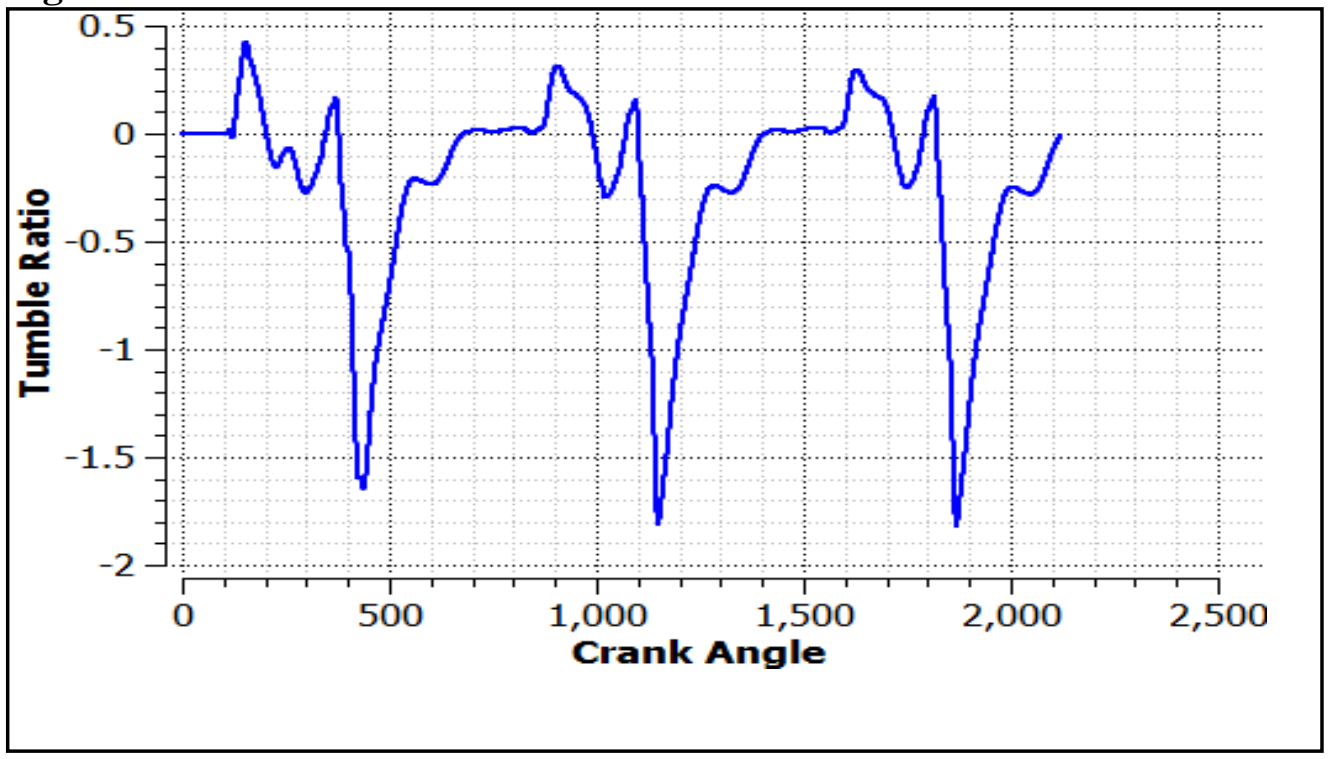


It is worth noting that the calculation was run for 3 engine cycles $(3 \times 4$ strokes) passing through the initial transients to achieve periodicity of the solution.

To validate the data obtained from the simulation, the pressure variation predicted by the model shown in Figure 10 reached a maximum of 23.5 bar which deviates by only $6.8 \%$ from that measured during the compression test ( 22 bar) (Amr et al., 2016). This deviation may be attributed to leakage which is hard to simulate in the model given the small clearance gap which would have required finer mesh that could lead to a significant increase in the computational time for minor improvement.

Figure 10. Cylinder Pressure vs. Crank Angles

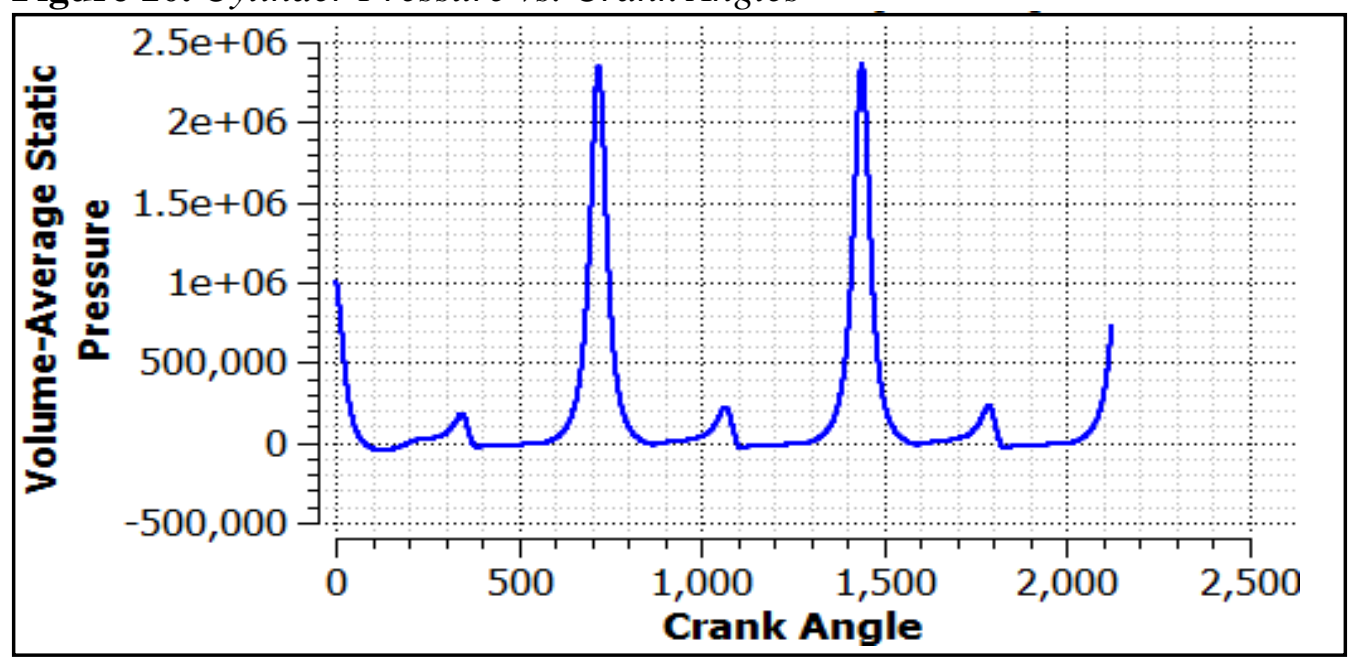

\section{Spray Model}

In any engine, the fuel atomization and spray formation facilitate liquid dispersion in a gaseous phase significantly increasing the interface between the two fluids which is favorable for mass and heat transfer. In Diesel engines the combustion process basically depends on the spray structure of the fuel and its interaction with the air within the combustion chamber.

For validation purposes, a simplified model of the spray injected in a constant volume chamber is developed and its predictions for comparison against experimental data published in the open literature (Nawi et al., 2015; Wang et al., 2016; Fattah et al., 2015; Turner et al., 2012). Specifically, experimental data by Park et al. (2010) was used for validation since the test conditions were quite close to those of the current engine conditions with a pressure of 20 bars at the end of the compression stroke as listed in Table 2.

Table 2. Park et al. (2009) Experimental Conditions

Injection pressure

Ambient pressure

Ambient temperature

Injection temperature
1200 bar

20 bar

$400 \mathrm{~K}$

$290 \mathrm{~K}$ 
Diesel fuel of $830 \mathrm{~kg} / \mathrm{m}^{3}$ density was injected from a six-hole injector with a hole diameter of $0.126 \mathrm{~mm}$ and length of $0.8 \mathrm{~mm}$. The simulation in the current work was done for only one hole given its injection flow rate profile shown in Figure 11.

Figure 11. Injection Flow Rate Profile

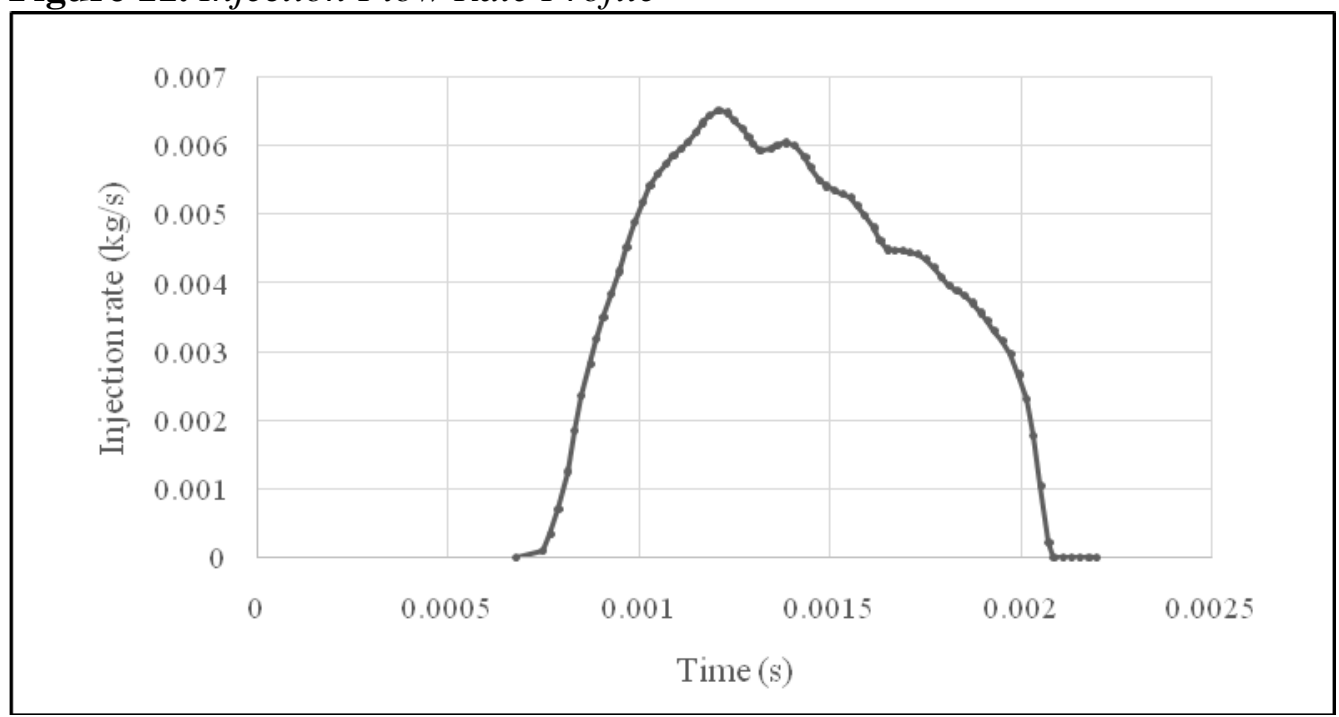

The constant volume chamber was modeled by a two-dimensional (2D) axi-symmetric rectangle using a structured grid of mesh size $1 \mathrm{~mm} \times 1 \mathrm{~mm}$ shown in Figure 12. The calculation domain had a length of $25 \mathrm{~cm}$ and a radius of 7.5 $\mathrm{cm}$ to prevent impingement of the spray onto the wall.

Figure 12. Chamber Mesh

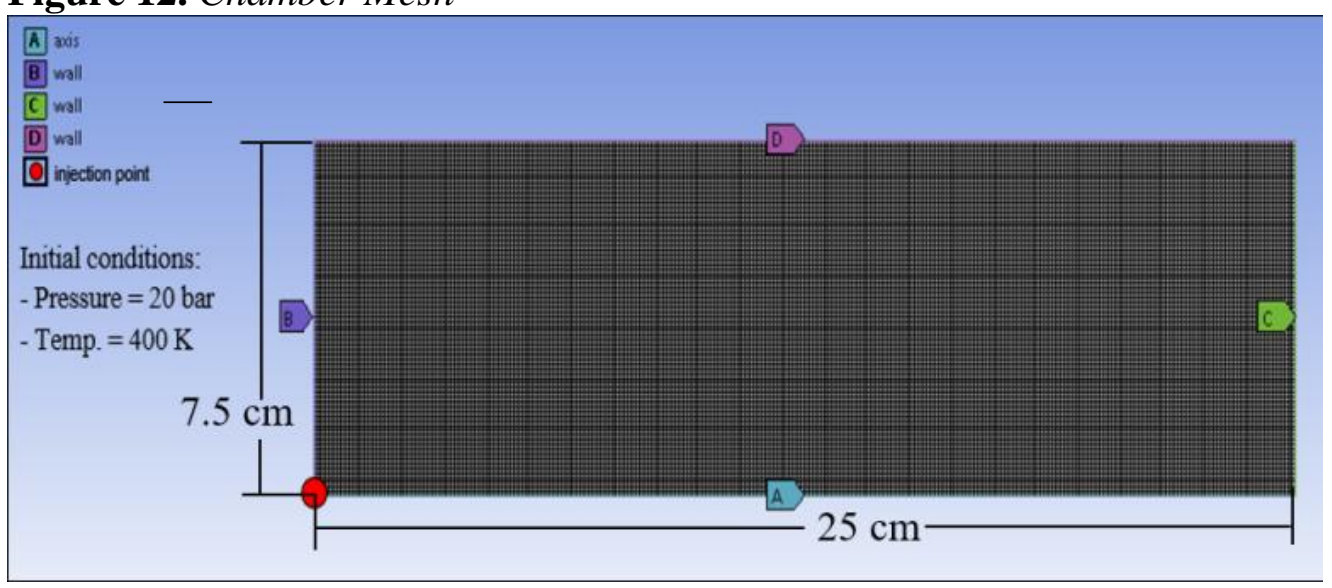

The spray formation process was modeled in ANSYS-FLUENT using the dispersed phase model (DPM) that solves the continuous phase with the Eulerian approach and tracks the spray particles with the Lagrangian approach. Two way coupling between the spray and the continuous phase is considered in the current model given the level of their mutual interaction with momentum, energy and 
mass exchanges. This coupling is achieved via mass, momentum and energy source terms. The mass source term is given by

$$
\begin{aligned}
& s_{\text {mass }}=-\frac{1}{V} \sum_{k} \dot{m}_{k} \\
& \dot{m}_{k}=\frac{d m}{d t}=\operatorname{Sh} \pi D \rho_{c} D_{v}\left(\omega_{A, s}-\omega_{A, \infty}\right)
\end{aligned}
$$

where $\dot{m}_{k}$ is the rate of mass transfer (evaporation) from particle $k$ into the volume of interest $V, S h$ is Sherwood number, $D$ is the particle diameter, $\rho_{c}$ is the average density between liquid density at the droplet surface and the freestream density, $D_{v}$ is the diffusion coefficient and $\omega_{A, s}$ and $\omega_{A, \infty}$ are the mass fraction of species $A$ at the droplet surface and in the free stream respectively.

The momentum source term along $x$ axis is given by

$$
s_{\text {mom }_{i}}=-\frac{1}{V} \sum_{k} v_{k, i} \dot{m}_{k}-\frac{1}{V} \sum_{k} F_{k, i}
$$

where $v_{k, i}$ is the particle $k$ velocity in $x$ direction. The first term represents the momentum flux via mass transfer and the second term represents the dynamic forces on the particle. Again the momentum source terms of $y$ and $z$ axes are similar to that of $x$ axis.

The energy source term is given by

$$
\begin{aligned}
S_{\text {energy }}=-\frac{1}{V} \dot{Q}_{k} & -\frac{1}{V} \sum_{k} v_{k, i} F_{k, i} \\
= & -\frac{1}{V} \sum_{k}\left[\epsilon \sigma \pi D^{2}\left(T_{k}{ }^{4}-T_{c}{ }^{4}\right)+N u \pi D k_{c}\left(T_{k}-T_{c}\right)\right] \\
& -\frac{1}{V} \sum_{k} v_{k, i} F_{k, i}
\end{aligned}
$$

where $\dot{Q}_{k}$ is the heat transfer rate to the particle, $\epsilon$ is the emissivity, $\sigma$ is the Stephan-Boltzmann constant, $N u$ is Nusselt number, $T_{k}$ is the particle temperature and $T_{c}$ is the continuous phase temperature (ANSYS).

The initial high momentum of the spray into a chamber of high pressure leads to the breakup of the droplets by higher drag forces mainly. Kelvin-Helmholtz Rayleigh-Taylor (KH-RT) model is recommended for spray formation modeling since simulates the spray breakup effectively (Afshar, 2014; Chryssakis and Kaiktsis, 2008; Reitz and Beale, 1999). This model combines the effects of Kelvin-Helmholtz waves driven by aerodynamic forces with Rayleigh-Taylor 
instabilities due to acceleration of shed drops ejected into freestream conditions. Both mechanisms model droplet breakup by tracking wave growth on the surface of the droplet, with breakup occurring due to the fastest growing instability based on local conditions.

Droplet velocities are maximum at the spray axis and decrease in the radial direction due to interaction with the entrained gas. In the dense spray, the probability of droplet collisions is high. These collisions can result in a change of droplet velocity and size. Droplets can break up into smaller ones, but they can also coalesce to form larger drops. The collision and coalescence models used in the current work are based on O'Rourke's algorithm (ANSYS; Hamdani et al., 2015). Figure 13 shows the progression of droplets breakup, dispersal and penetration in the domain.

\section{Figure 13. Spray Growth through the Domain with Time}

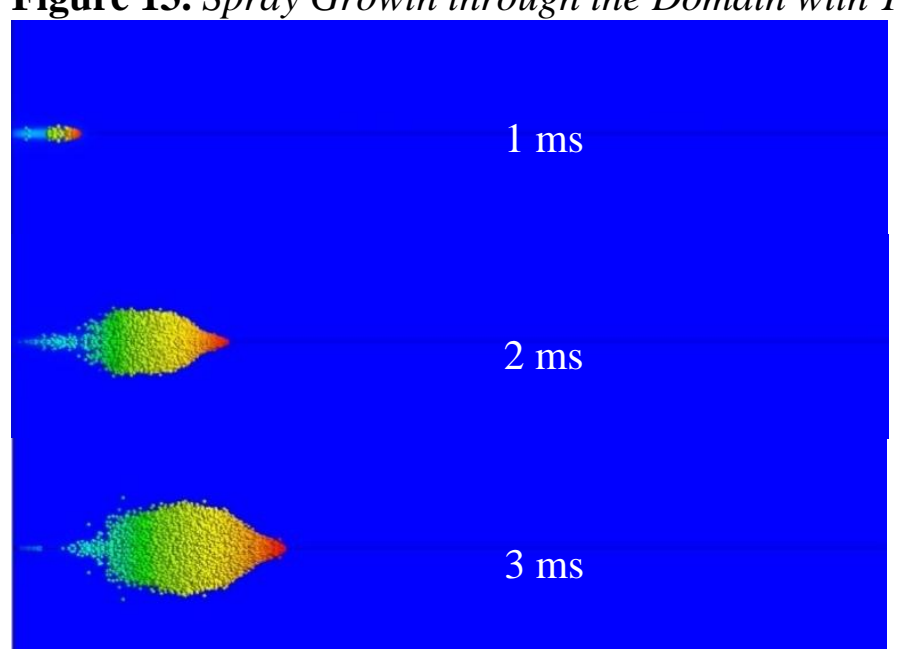

The spray-air interaction is a two-way coupled phenomenon as the velocity of the air in the domain increases from zero to about $45 \mathrm{~m} / \mathrm{s}$ at the core of the spray and so does the particles velocities averaged over each cell (DPM velocity) decreases from about $55 \mathrm{~m} / \mathrm{s}$ to zero at the edges of the spray as shown in Figure 14. This concept is also present in the temperature as we can see in Figure 15 that the temperature of the domain decreased from $400 \mathrm{~K}$ to about $370 \mathrm{~K}$ at the core of the spray while the DPM temperature increased from 290 $\mathrm{K}$ to about $375 \mathrm{~K}$ inside the spray cloud. 
Figure 14. Contours of Domain and DPM Velocities

Velocity

$4.424 \mathrm{e}+001$
$4.192 \mathrm{e}+001$
$3.959 \mathrm{e}+001$
$3.726 \mathrm{e}+001$
$3.493 \mathrm{e}+001$
$3.260 \mathrm{e}+001$
$3.027 \mathrm{e}+001$
$2.794 \mathrm{e}+001$
$2.561 \mathrm{e}+001$
$2.329 \mathrm{e}+001$
$2.096 \mathrm{e}+001$
$1.863 \mathrm{e}+001$
$1.630 \mathrm{e}+001$
$1.397 \mathrm{e}+001$
$1.164 \mathrm{e}+001$
$9.314 \mathrm{e}+000$
$6.986 \mathrm{e}+000$
$4.657 \mathrm{e}+000$
$2.329 \mathrm{e}+000$
$0.000 \mathrm{e}+000$

$\left[m s^{n}-1\right]$

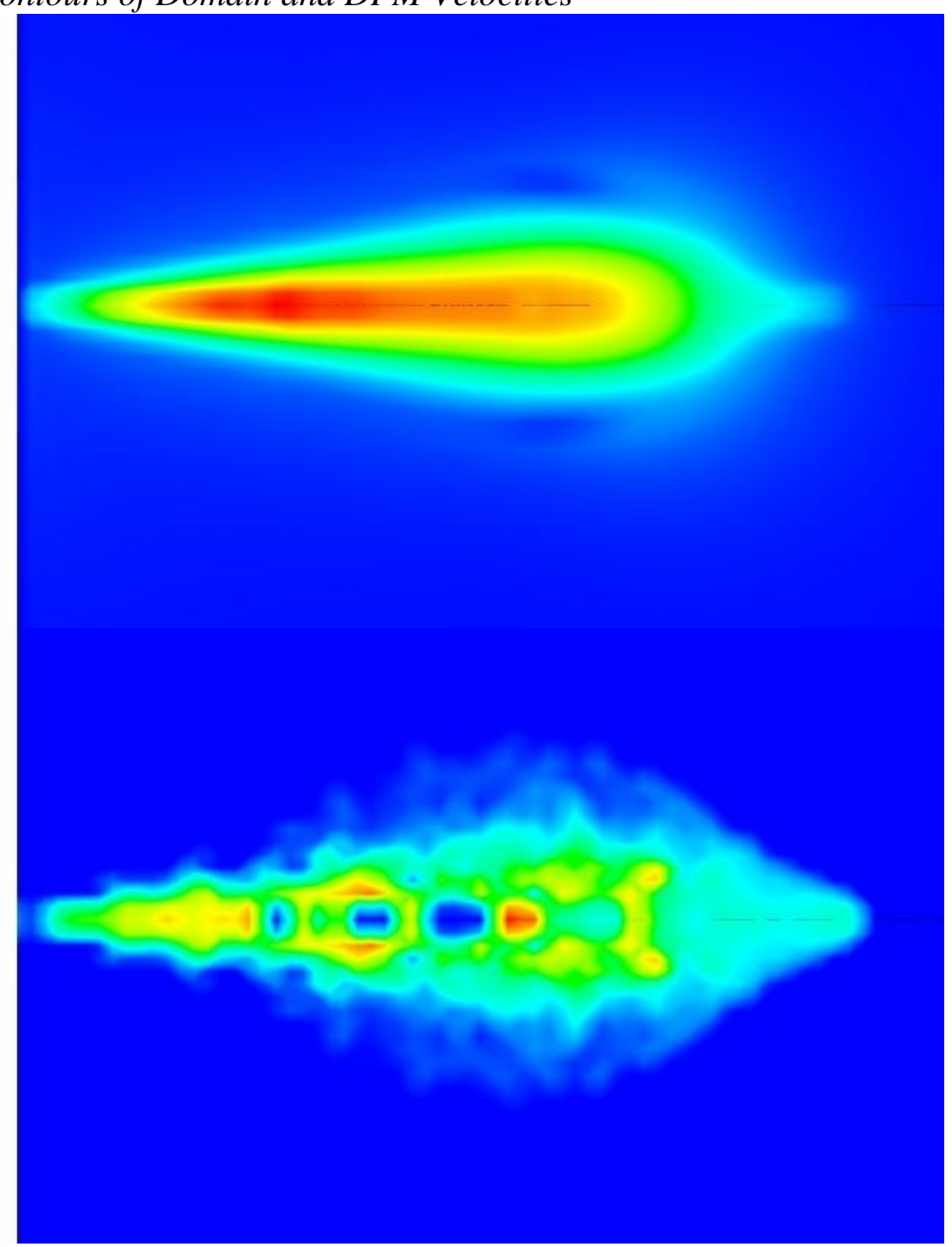
Contour 1
$5.517 \mathrm{e}+001$
$5.226 \mathrm{e}+001$
$4.936 \mathrm{e}+001$
$4.645 \mathrm{e}+00$
$4.355 \mathrm{e}+00$
$4.065 \mathrm{e}+00$
$3.774 \mathrm{e}+001$
$3.194 \mathrm{e}+001$
$2.903 \mathrm{e}+00$
$2.613 e+001$
$2.323 \mathrm{e}+001$
$2.032 \mathrm{e}+001$
$1.742 \mathrm{e}+001$
$1.452 \mathrm{e}+001$
$1.161 \mathrm{e}+001$
$8.710 \mathrm{e}+000$
$5.807 \mathrm{e}+000$
$2.903 \mathrm{e}+000$

[m s^-1] 
Figure 15. Contours of Domain and DPM Temperatures

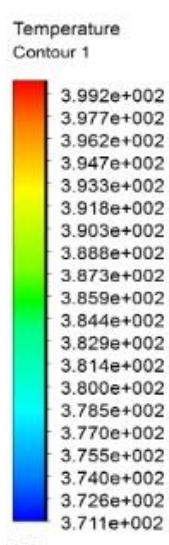

[K]

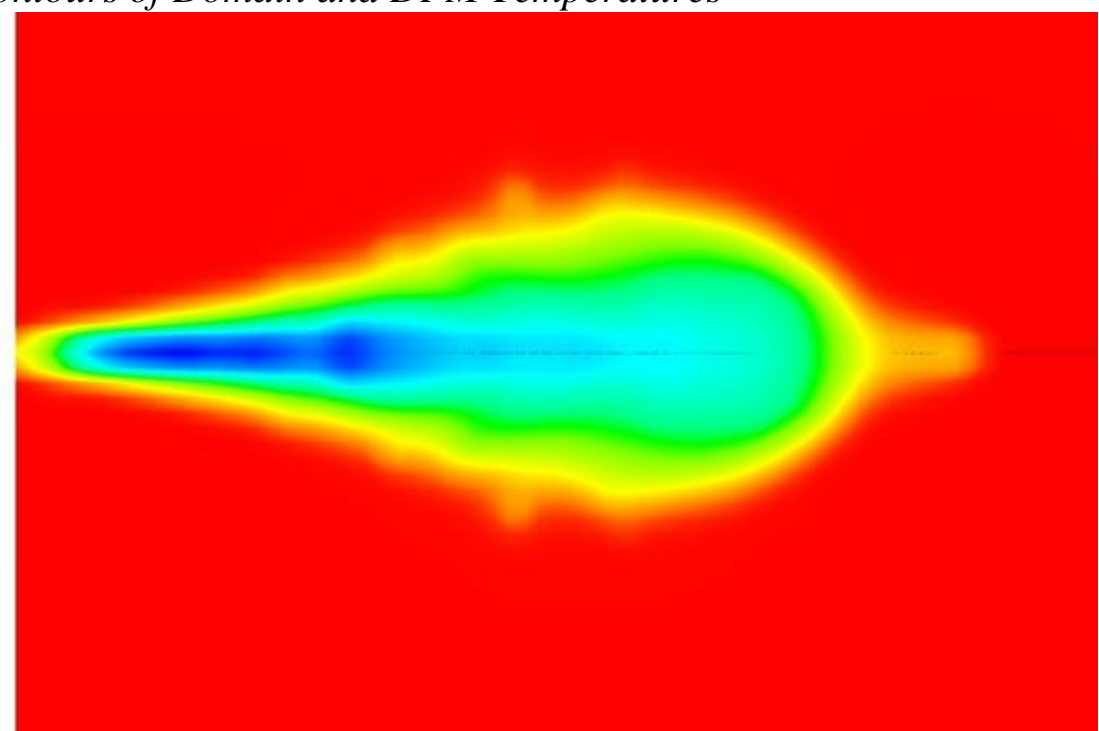

Dpm Temperature Contour 1

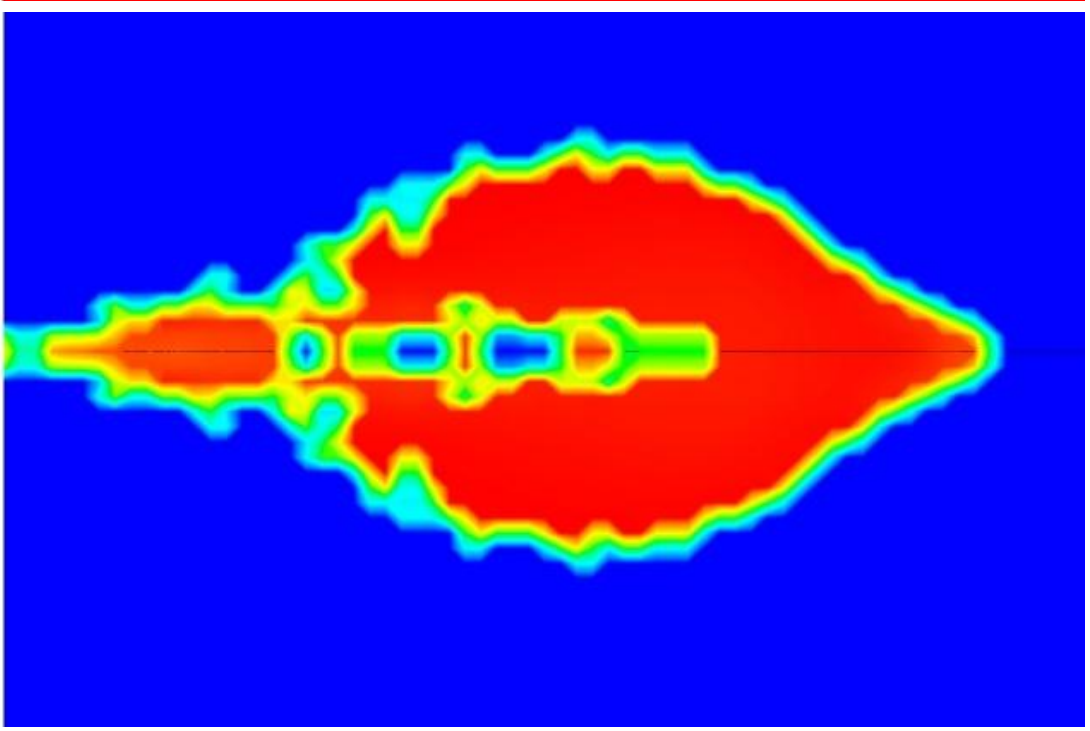

The model prediction of the progression of the spray penetration length in time is compared with experimental data measured by Park et al. (2010) under similar conditions as shown in Figure 16. The comparison indicates that the model has not only captured the qualitative behavior of the spray but also achieved reasonable quantitative agreement. 
Figure 16. Penetration Length Curves for Real Spray and Modeled Spray

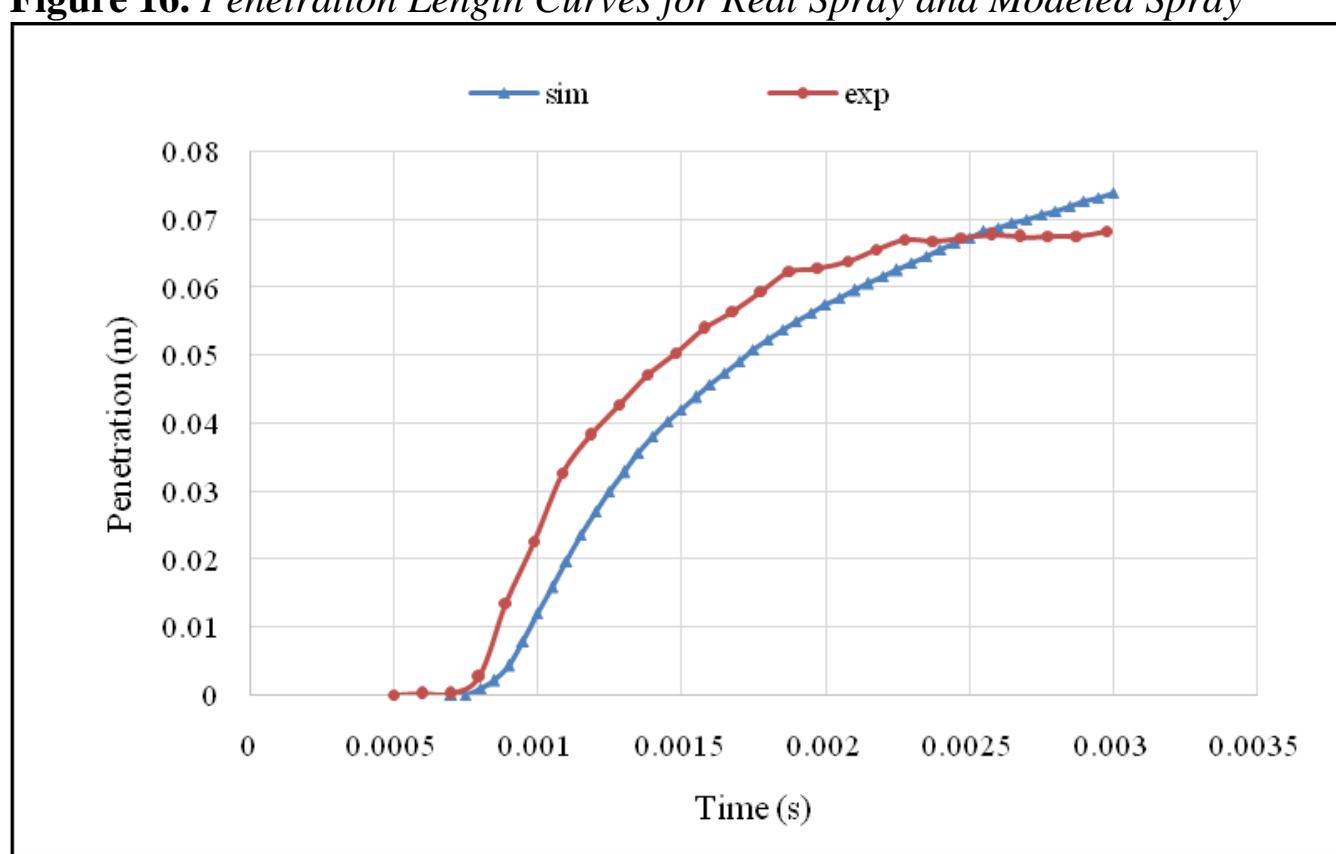

Now that the engine model has been validated against experimental data, it was interesting to explore how the model predicts the spray behavior under different operating and/or design conditions. It is important to note here that the injection in current engine is mechanical with lower injection pressures than that used in the validation process but it is assumed that the breakup and atomizer models hold for the pressure range under investigation.

\section{Engine Cold Flow Simulation with Diesel Injection}

Different cases were studied to gain better understanding of the dependence of spray characteristics on different operational and geometric parameters, for example: the attendant pressures as well as injector nozzle diameter. Ruggerini RD 270 engine uses a 4-hole traditional mechanical injection system with its design details summarized in Table 3.

Table 3. Ruggerini RD 270 Injector Specifications

Nozzle diameter $\quad 0.00028 \mathrm{~m}$

$\begin{array}{lll}\text { Case } 1 & \text { Nozzle length } & 0.00056 \mathrm{~m} \\ & \text { Injection pressure } & 350 \mathrm{bar}\end{array}$

Injection mass flow rate $0.008738 \mathrm{~kg} / \mathrm{s}$

The average injection mass flow rate can be determined by the following equation:

$$
\dot{m}_{f}=C_{f} A_{o} \sqrt{2 \rho_{f} \Delta P}
$$


where $\dot{m}_{f}$ is the average injection mass flow rate per hole per cylinder pet cycle, $C_{f}$ is the flow coefficient through the orifice, $A_{o}$ is the orifice cross sectional area, $\rho_{f}$ is the fuel density and $\Delta P$ is the pressure difference between the injection pressure and the chamber pressure.

The predicted spray penetration length under these conditions, referred to as Case 1, is shown in Figure 17. It should be noted that angle zero is taken at the start of the injection process.

Figure 17. Case 1 Penetration Curve

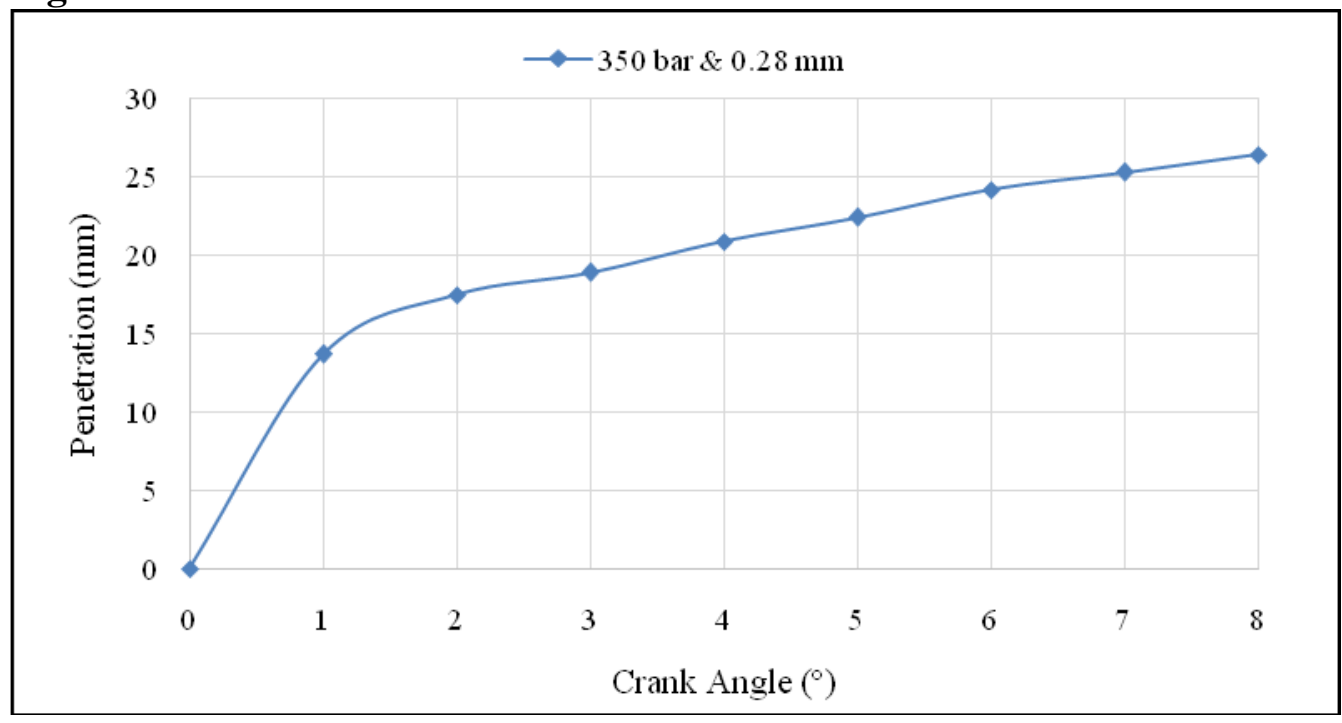

Though Case 1 simulates the engine conditions using an injection pressure of 350 bar, higher injection pressures (500 and 650 bar) were tested and compared to Case 1. As expected, with higher injection pressures, higher flow rates are encountered with the same injector diameter and injection period. Predictions of these two cases (Cases 2 and 3) are given in Table 4.

Table 4. Higher Injection Pressures Cases

$\begin{array}{lcc} & \text { Case 2 } & \text { Case 3 } \\ \text { Nozzle diameter }(\mathrm{m}) & 0.00028 & 0.00028 \\ \text { Nozzle length }(\mathrm{m}) & 0.00056 & 0.00056 \\ \text { Injection pressure (bar) } & 500 & 650 \\ \text { Injection mass flow rate }(\mathrm{kg} / \mathrm{s}) & 0.010558 & 0.012108\end{array}$

Cases 1, 2, and 3 are compared in Figure 18, clearly increasing the injection pressure imparts more momentum to the spray and hence increases its penetration length. 
Figure 18. Penetration Curves for Cases 1, 2 and 3

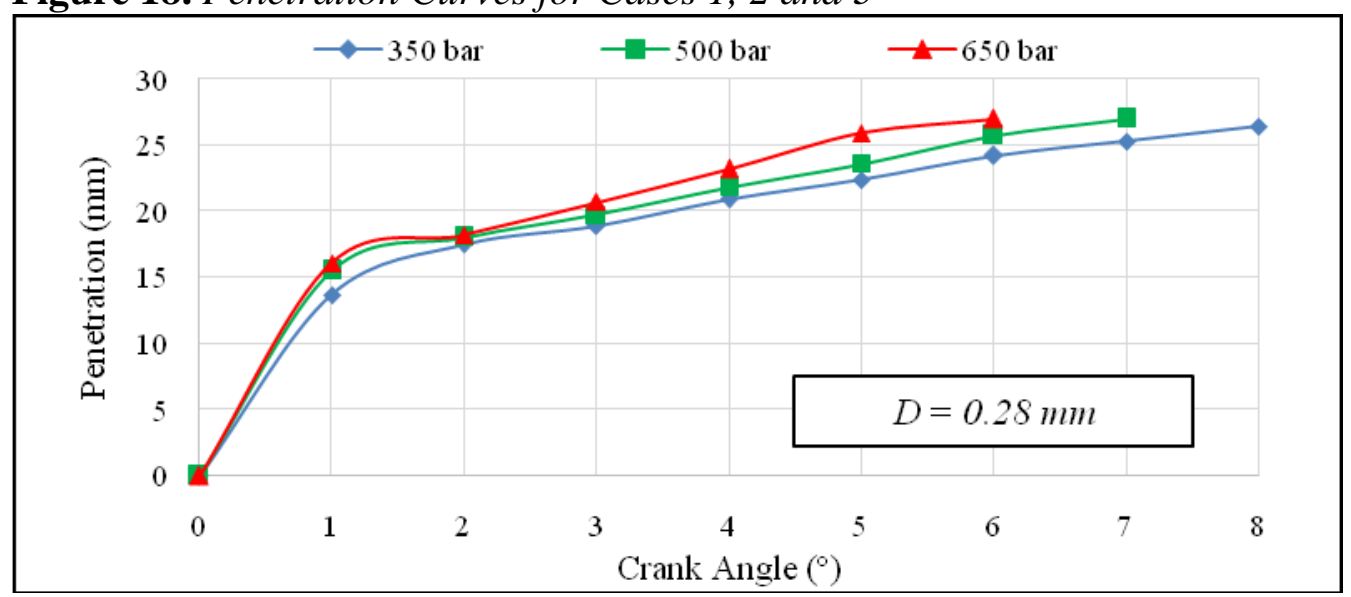

Now the effect of changing injector hole diameter while keeping the injection pressure, injection period as well as the nozzle's length-to-diameter ratio constant is investigated. The model predictions under these two conditions (Cases 4 and 5) are given in Table 5 .

Table 5. Larger Injection Diameters Cases

Nozzle diameter $(\mathrm{m})$

Case 4

0.00035

0.0007

350

Injection pressure (bar)

Injection mass flow rate $(\mathrm{kg} / \mathrm{s})$

\section{Case 5 \\ 0.0004 \\ 0.0008 \\ 350 \\ 0.017861}

Cases 1, 4, and 5 are compared in Figure 19. To highlight the impact of nozzle diameter on the penetration length. Increasing the nozzle diameter for the same injection pressure increases the penetration length as more fuel is injected and hence higher momentum is imparted to the spray hence achieving a longer penetration length.

Figure 19. Penetration Curves for Cases 1, 4 and 5

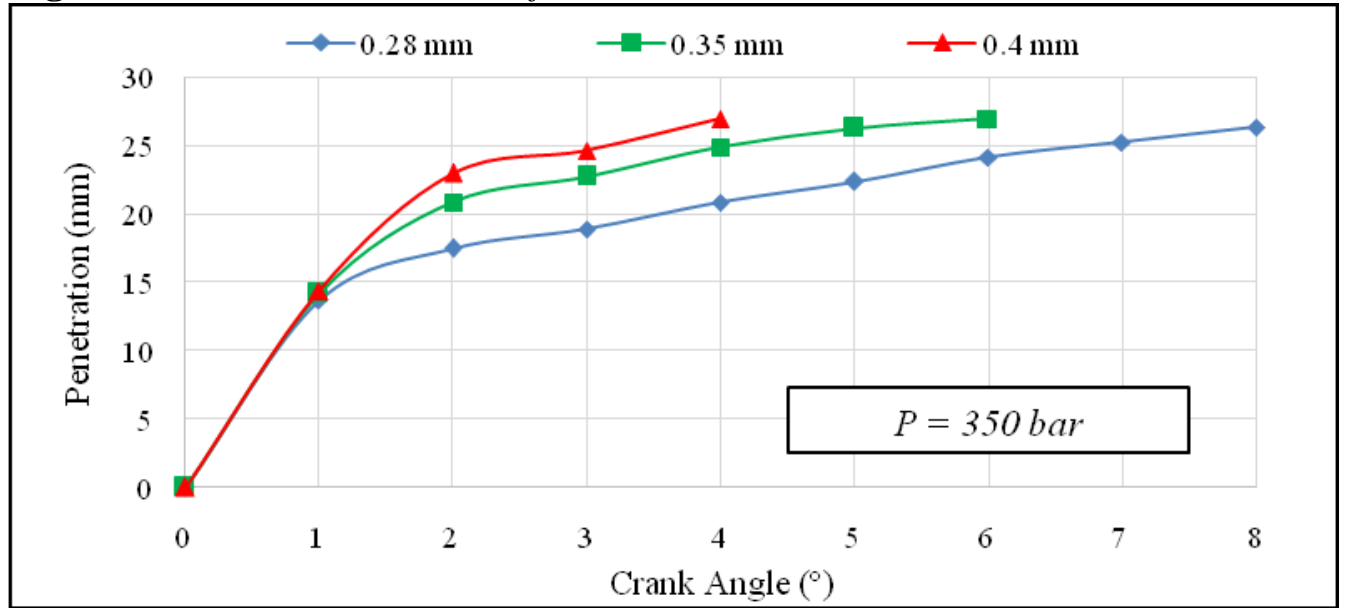


The previous cases focused on the impact of injection pressures and diameters on the spray behavior without taking into consideration the stoichiometric condition inside the combustion chamber. Usually, Diesel engines operate airto-fuel ratios of about 15:1, i.e. with lean and definitely not rich or stoichiometric mixtures at all load conditions. This is necessary to ensure proper mixing between the fuel vapor and the air before the end of combustion. The stoichiometric reaction for the combustion of Diesel fuel with air is represented by

$$
\mathrm{C}_{10} \mathrm{H}_{22}+15.5\left(\mathrm{O}_{2}+3.76 \mathrm{~N}_{2}\right) \rightarrow 10 \mathrm{CO}_{2}+11 \mathrm{H}_{2} \mathrm{O}+58.28 \mathrm{~N}_{2}
$$

The air-to-fuel $(A F)$ ratio in the previous reaction equals 14.98. Air mass in the chamber before the injection was calculated in the simulation and found to be $0.000697 \mathrm{~kg}$. The injection period for all the cases in the simulation was $20^{\circ}$ crank angle with the engine running at $3000 \mathrm{rpm}$ so the injected fuel mass through the 4 holes of the injector for each case could be calculated. Table 6 shows the $A F$ ratios for all the cases and the excess air factor $\lambda$ for each one which is defined as the ratio between the actual $A F$ ratio to the stoichiometric one.

Table 6. Air-to-fuel Ratio and Excess Air Factor for Cases 1, 2, 3, 4 and 5

$\begin{array}{ccc}\text { Case } & A F & \lambda \\ 1 & 17.95 & 1.198 \\ 2 & 14.85 & 0.991 \\ 3 & 12.95 & 0.864 \\ 4 & 11.47 & 0.766 \\ 5 & 8.78 & 0.586\end{array}$

It seems that the mixtures of Cases 2, 3, 4 and 5 are all rich and hence unrealistic since it will be difficult to burn all of the fuel particles thus leading to soot formation. Therefore, another simulation was performed to study the spray behavior if the injection pressures and diameters were changed while keeping the fuel mass flow rate constant and hence a constant $A F$ ratio. In this study the injection pressures used ranged from 350 bar to 1200 bar like those used in modern common rail injection systems. The injection mass flow rate was kept at $0.008738 \mathrm{~kg} / \mathrm{s}$ like Case 1 . Table 7 shows the data of the new three cases.

Table 7. Constant Injection Flow Rate Cases

$\begin{array}{lccc} & \text { Case 6 } & \text { Case 7 } & \text { Case 8 } \\ \text { Nozzle diameter }(\mathrm{m}) & 0.00024 & 0.00022 & 0.0002 \\ \text { Nozzle length }(\mathrm{m}) & 0.00048 & 0.00044 & 0.0004 \\ \text { Injection pressure (bar) } & 600 & 900 & 1200 \\ \text { Injection mass flow rate }(\mathrm{kg} / \mathrm{s}) & 0.008738 & 0.008738 & 0.008738\end{array}$

The resultant penetration curves for these cases are shown in Figure 20. Initially, particles issuing from larger holes will penetrate further than those 
issuing from their smaller counterparts since the momentum of the former is much higher due to their larger mass. However, this behavior doesn't last too long as the effect of higher injection velocity due to the higher pressure difference dominates as such the fuel particles reach the walls of the chamber before those injected with lower pressures.

Figure 20. Penetration Curves for Cases 1, 6, 7 and 8

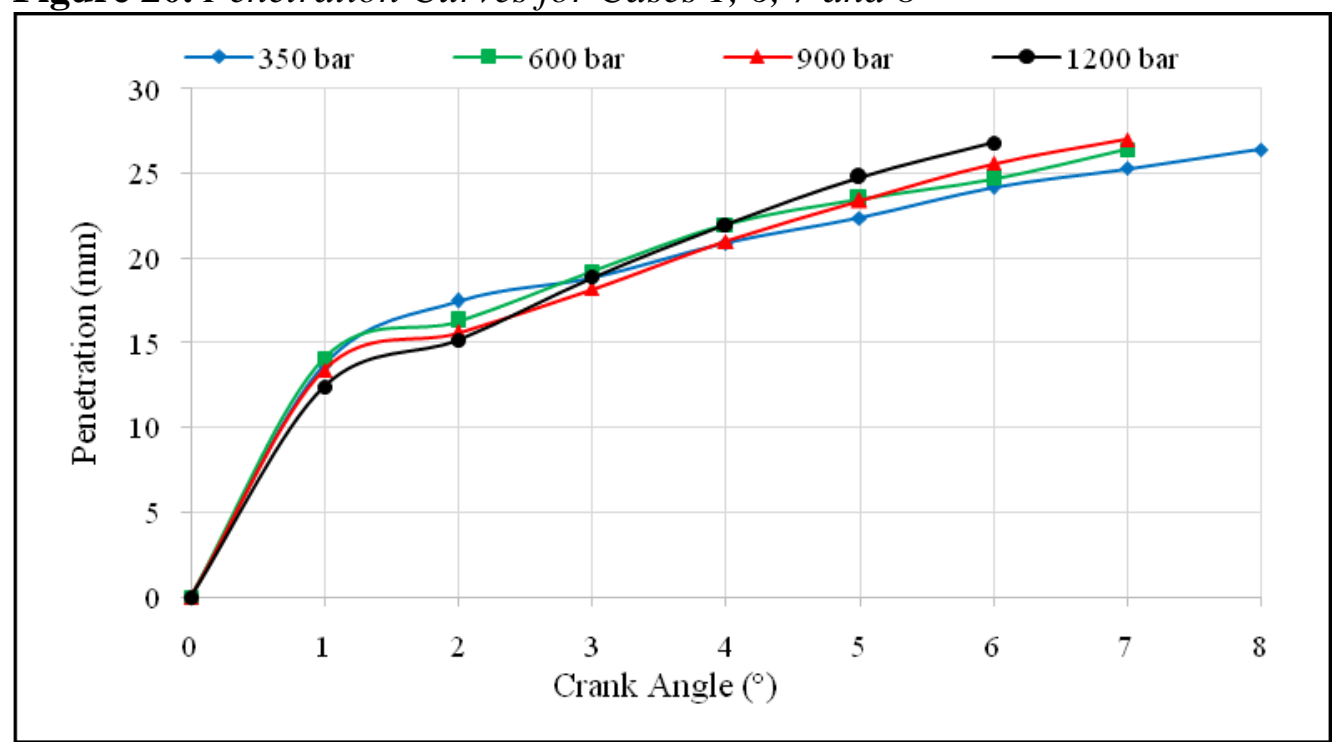

\section{Conclusions}

A CFD model of a Ruggerini RD 270 was implemented and validated against experimental data by Park et al. and a compression test performed in house; both showed a good agreement. The validated spray model was integrated into the engine simulation to gain better understanding of the spray characteristics inside the engine under different operational as well as geometrical parameters. Specifically, the effect of injection pressure at constant injection diameter was studied and the model showed that a $30 \%$ increase in the injection pressure had little effect on the penetration length. Additionally, the effect of increasing the injection diameter at constant injection pressure was also studied and was shown to have a significant effect on the penetration length. This is attributed to the fact that increasing the particles with larger nozzle diameters increases their momentum which allows them to move faster into the domain before they breakup into smaller droplets. Finally, both the injection pressure, as well as the injection nozzle diameter, were changed while keeping the injection mass flow rate constant and hence, the overall air-to-fuel ratio constant. For this latter simulation, the injection pressure range used was in the range of that used in common rail systems. Consequently, particles penetrated further in the computational domain just after the start of injection irrespective of their size, due to the large momentum imparted to them. However, this may be problematic 
since fuel particles may reach the engine walls before they fully evaporate, which implies the need for optimization.

\section{Future Work}

Though the cold flow simulation is an important milestone in the current research program, however, we'd like to extend the work to include both combustion and emissions models. Additionally, it is planned to compare the engine performance using different blends of biodiesel fuel to petrol diesel under different operating and/or design parameters.

\section{Acknowledgments}

This research was made possible by the financial support of Ain Shams University 2014/2015 Research Grant. The authors wish to express their deep gratitude.

\section{Nomenclature}

\begin{tabular}{cc}
$p_{s}$ & Piston location \\
TDC & Top dead center \\
BDC & Bottom dead center \\
$L$ & Connecting rod length \\
$A$ & Piston stroke \\
$\theta_{c}$ & Current crank angle \\
$\theta_{s}$ & Starting crank angle \\
$N$ & Crank shaft speed \\
$t$ & Time \\
$\rho_{a}$ & Density of the air \\
$u$ & Velocity components of axis $x$ \\
$v$ & Velocity components of axis $y$ \\
$w$ & Velocity components of axis $z$ \\
$P$ & Pressure \\
$v$ & Flow velocity \\
$\tau_{x x}$ & Normal stress in $x$ direction \\
$\tau_{y x}$ & Shear stresses parallel to $x$ and normal to $y$ \\
$\tau_{z x}$ & Shear stresses parallel to $x$ and normal to $z$ \\
$\alpha_{a}$ & Void fraction of the air \\
$i_{a}$ & Air internal energy \\
$\dot{q}$ & Rate of volumetric heat addition per unit mass \\
$k_{e f f}$ & Effective thermal conductivity \\
$s_{m a s s}$ & Mass source term \\
$s_{m o m}$ & Momentum source term \\
\hline &
\end{tabular}




\begin{tabular}{|c|c|}
\hline$s_{\text {energy }}$ & Energy source term \\
\hline$k$ & Turbulent kinetic energy \\
\hline$\varepsilon$ & Turbulent kinetic energy dissipation rate \\
\hline$\mu_{t}$ & Turbulent viscosity \\
\hline$P r_{t}$ & Turbulent Prandtl number \\
\hline$M_{t}$ & Turbulent Mach number \\
\hline$m_{k}$ & Rate of mass transfer from particle $k$ \\
\hline$V$ & Volume \\
\hline$S h$ & Sherwood number \\
\hline$D$ & Particle diameter \\
\hline$\rho_{c}$ & $\begin{array}{l}\text { Average density between liquid density at the droplet surface and the } \\
\text { freestream density }\end{array}$ \\
\hline$D_{v}$ & Diffusion coefficient \\
\hline$\omega_{A, s}$ & Mass fraction of species A at the droplet surface \\
\hline$\omega_{A, \infty}$ & Mass fraction of species A in the free stream \\
\hline$v_{k, i}$ & Velocity of particle $k$ in $x$ direction \\
\hline$F_{k, i}$ & Fluid dynamic forces on particle $k$ in $x$ direction \\
\hline$\dot{Q}_{k}$ & Heat transfer rate to particle $k$ \\
\hline$\epsilon$ & Emissivity \\
\hline$\sigma$ & Stephan-Boltzmann constant \\
\hline $\mathrm{Nu}$ & Nusselt number \\
\hline$T_{k}$ & Particle temperature \\
\hline$T_{c}$ & Continuous phase temperature \\
\hline$\dot{m}_{f}$ & Average injection mass flow rate per hole per cylinder pet cycle \\
\hline$C_{f}$ & Flow coefficient through the orifice \\
\hline$A_{o}$ & Orifice cross sectional area \\
\hline$\rho_{f}$ & Fuel density \\
\hline$\Delta P$ & $\begin{array}{c}\text { Pressure difference between the injection pressure and the chamber } \\
\text { pressure }\end{array}$ \\
\hline
\end{tabular}

\section{References}

Afshar, A. (2014) 'Evaluation of liquid fuel spray models for hybrid RANS/LES and DLES prediction of turbulent reactive flows', Graduate Department of Aerospace Engineering, University of Toronto.

Amr E., Omar E., Amr K. and Hazem S. (2016) 'Design and construction of variable compression ratio modification on a 4-stroke double cylinder diesel engine', Graduation Project Report, Mechanical Power Department, Ain Shams University.

ANSYS® Academic Research, Release 16, Help System, FLUENT theory guide, ANSYS, Inc.

Chryssakis, C. and Kaiktsis, L. (2008) 'Evaluation of Fuel Spray Atomization Models for Conditions Applicable to Large Marine Diesel Engines', in ILASS.

Crowe, C. T., Sommerfeld, M. and Tsuji, Y. (1998) Multiphase Flows with Droplets and Particles, CRC Press New York. doi: 10.1201/b11103-4. 
Fattah, I. M. R. et al. (2015) 'Macroscopic Spray Characteristics of an Evaporating Diesel Spray', in Australian Combustion Symposium, pp. 1-4.

Hamdani, A. et al. (2015) 'Numerical simulations on droplet coalescence in an L-shaped duct for inlet fogging of gas turbine engines', International Journal of Gas Turbine, Propulsion and Power Systems, 7(1), pp. 1-9.

Munoz, R. A. A. et al. (2012) 'Biodiesel: Production, Characterization, Metallic Corrosion and Analytical Methods for Contaminants', Biodiesel - Feedstocks, Production and Applications, p. 48. doi: 10.5772/53655.

Nawi, M. A. M. et al. (2015) 'Droplets Behavior and Evaporation of Diesel Spray Affected by Ambient Density after Pilot Injection', in JSAE/SAE 2015 Small Engine Technologies Conference \& Exhibition.

Park, S. H., Kim, H. J. and Lee, C. S. (2010) 'Comparison of experimental and predicted atomization characteristics of high-pressure diesel spray under various fuel and ambient temperature', Journal of Mechanical Science and Technology, 24(7), pp. 1491-1499.

Reitz, R. D. and Beale, J. C. (1999) 'Modeling Spray Atomization With the KelvinHelmholtz/Rayleigh-Taylor Hybrid Model', Atomization and Sprays, 9(6), pp. 623-650. doi: 10.1615/AtomizSpr.v9.i6.40.

Ruggerini Work Shop Manual (2003), RD series engines, p.no. 1-5302-620, RD 270.

Sushma, H. and Jagadeesh, K. B. (2013) 'CFD modeling of the in-cylinder flow in direct-injection Diesel engines’, International Journal of Scientific and Research Publications, 3(12).

Turner, M. R. et al. (2012) 'A breakup model for transient Diesel fuel sprays', Fuel. Elsevier Ltd, 97, pp. 288-305. doi: 10.1016/j.fuel.2012.01.076.

Wang, Z. et al. (2016) 'Macroscopic and microscopic characterization of diesel spray under room temperature and low temperature with split injection', Fuel Processing Technology, 142 (February), pp. 71-85. doi: 10.1016/j.fuproc.2015.10.007. 